\title{
Numerical Simulation of Emission Characteristics for Single-Cylinder Diesel Engine
}

\author{
Changwei Ding1, Weijun Liu ${ }^{2}$ \\ ${ }^{1}$ College of Automotive Engineering, Shanghai University of Engineering and Science, Shanghai, China \\ ${ }^{2}$ College of Mechanical Engineering, Shanghai University of Engineering and Science, Shanghai, China \\ Email:728965487@qq.com, Iwj1119@139.com
}

Received 24 December 2015; accepted 22 February 2016; published 25 February 2016

Copyright (C) 2016 by authors and Scientific Research Publishing Inc.

This work is licensed under the Creative Commons Attribution International License (CC BY).

http://creativecommons.org/licenses/by/4.0/

(c) (i) Dpen Access

\begin{abstract}
First, the geometry model and the calculation mesh of single-cylinder direct injection diesel engine are built, using ESE module of the 3D simulation software AVL FIRE v2014 [1]. Then, by setting appropriate boundary condition, initial condition and calculating step length, and selecting spray, the burning emissions on model and on the basis of adjusting the parameters, a scientific and reasonable simulation platform is built. Emission characteristics of single-cylinder diesel engines in oxygen-enriched, oxygen-enriched + EGR (inlet adding $\mathrm{CO}_{2}$ ), and separately using EGR would be studied. It is concluded that EGR synergy oxygen-enriched combustion is beneficial to exhaust treatment and $21 \% \mathrm{CO}_{2}+23 \%$ oxygen content is the optimal matching to improve diesel engine exhaust emissions.
\end{abstract}

\section{Keywords}

Single-Cylinder Diesel Engine, EGR, Oxygen-Enriched Combustion, Numerical Simulation

\section{Introduction}

Diesel engine is a power plant of the highest efficiency of all the internal combustion engines; it has good power performance, economy and durability, more and more widely used in all kinds of vehicles and power plant. Because of all kinds of advanced technology used in diesel engine, it also gradually changes to the engine of high efficiency and energy saving from the traditional one of heavy smoke and big noise. However, along with the people's environmental protection consciousness enhancement and increasingly stringent emission regulations [2], the technology that controls its emissions has become a key factor for the popularization and application of 
diesel engine. Especially for single-cylinder diesel engine, a very effective way to control its emissions is lacking [3]. Currently, oxygen-enriched combustion is a way to reduce diesel's particulate emissions, and at the same time, it also can bring some negative effects. For example, the emissions of NOx will increase. Oxygenrich and high temperature areas are places where NOx is produced, so oxygen-enriched combustion cannot fundamentally solve problems of diesel engine exhaust emissions. Exhaust gas recirculation (EGR) has been widely applied to vehicle, but it also has some certain problems. It will inevitably lead to decline in power performance, and this is fatal for diesel engine. The fuel is not fully burning, then particulate matter will become more. ThreeWay Catalyst can effectively solve problems about emissions of NOx and particulate matter, but it has special requirements. Now it is rarely used in diesel engine, especially single-cylinder diesel engine. Integrating advantages and disadvantages of current emission control technology, this paper puts forward a kind of new method of EGR + oxygen-enriched combustion, to reduce single-cylinder diesel engine's emissions, and further to meet the requirements of the emission regulations.

\section{The Models of Simulation Calculation}

For compression ignition engine, using AVL FIRE v2014 to simulate mainly include building geometry model of engine according to the structural parameters of combustion chamber, meshing of the combustion chamber geometry model, according to the experiment data and experience set the combustion initial conditions, boundary conditions, etc., selecting the appropriate gas flow model, the combustion model and emission model.

\subsection{Setting Geometry Model of Combustion Chamber}

In this paper, regarding single-cylinder diesel engine as the research object, the basic parameters and boundary conditions are shown in Table 1.

The type of single-cylinder diesel engine's combustion chamber shape is $\omega$, pit center deviating from the cylinder center slightly, and simplifying it was symmetrical based on the center of the cylinder combustion chamber. To shorten the calculation time, combustion chamber is simplified according to the number of injector nozzle, and only calculates the single spray hole corresponding to the combustion chamber. By ESE module of the FIRE, combustion chamber geometry simulation model is established and it is shown in Figure 1.

Table 1. Main structural and operational parameters of diesel engine.

\begin{tabular}{|c|c|c|}
\hline Name & Unit & Parameter \\
\hline Cylinder Diameter & $\mathrm{mm}$ & 105 \\
\hline The Length of Connecting Rod & $\mathrm{mm}$ & 200 \\
\hline The Piston Stroke & $\mathrm{mm}$ & 120 \\
\hline Nozzle and Aperture & $\mathrm{mm}$ & $7 \times 0.216$ \\
\hline Injection Time & deg & $714-734$ \\
\hline Temperature of the Fuel Injection & $\mathrm{K}$ & 330.15 \\
\hline The Initial Inlet Temperature & $\mathrm{K}$ & 386 \\
\hline The Temperature of Cylinder Wall & $\mathrm{K}$ & 470 \\
\hline Cylinder Head Temperature & $\mathrm{K}$ & 570 \\
\hline The Piston Surface Temperature & $\mathrm{K}$ & 570 \\
\hline Compression Ratio & - & $16: 1$ \\
\hline Fuel Injection Quantity per Cycle & $\mathrm{kg}$ & $1.7286 \mathrm{e}^{-5}$ \\
\hline Engine Speed & $\mathrm{r} / \mathrm{min}$ & 2000 \\
\hline The Turbulence Model & - & K-ZETA-F \\
\hline The Nozzle Type & - & Pinhole Type \\
\hline The Initial Pressure in Cylinder & $\mathrm{MPa}$ & 0.256 \\
\hline
\end{tabular}




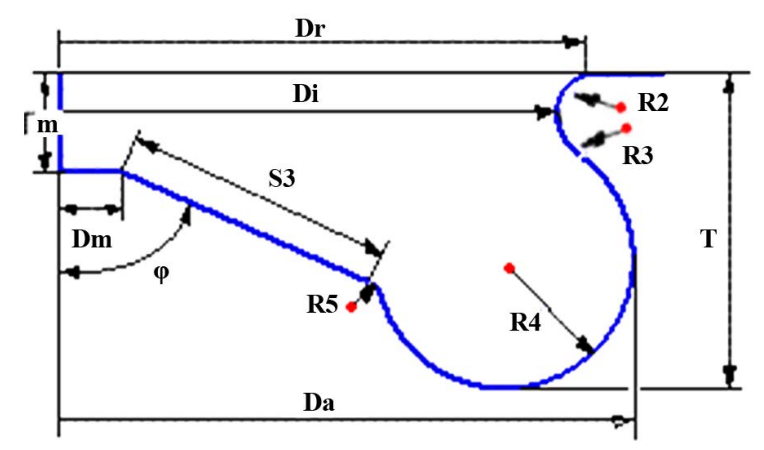

Figure 1. Combustion chamber shape.

\subsection{Calculation Mesh}

Due to the existence of a piston reciprocating motion, Multi-dimensional numerical simulation that application of dynamic grid can truly reflect the actual working condition in diesel engine. In order to shorten the calculation time, in this article, dynamic grid from the inlet valve close to the exhaust valve opens is built. Hexahedral grid was used and one seventh of the combustion chamber was divided. In the process of the whole simulation, the size and number of grids on piston top face are fixed, only with the piston movement. The grid number is 1496 and special position's (top and bottom dead center) grid diagrams are shown in Figure 2.

\subsection{Selection of Other Parameters and Models [4]}

In this article, the EGR rate was expressed in $\mathrm{CO}_{2}$ in the inlet, the gas flow in cylinder according to the solution of conservation of mass, momentum and energy conservation equations. In order to the equations of closed, need to build a complete simulation model and to select suitable operating parameters. Relevant Models are as follows: Combustion Model is Coherent Flame Model, NOx generation Model chooses the Extend Zeldovich, Soot generation Model selects the Kinetic Model, Spray son Model uses Turbulent dispersion Model, the evaporation Model adopts Dukowicz, broken Model chooses Wave. The relevant operation parameters are as shown in Table 1.

\subsection{Verifying the Model}

With the model diesel engine (2000 r/min and full load), the comparison of the pressure's values of cylinder measured by numerical simulation and experimental testing was shown in Figure 3. The diagram shows that the trend of cylinder pressure by numerical simulation and actual measurement almost is same. Meanwhile, the result of numerical simulation also is different from engine bench test. There exists difference mainly in this paper, the cause of geometric model is established based on combustion chamber and turbulence intensity at the end of inlet is obtained by empirical formula. Also some boundary conditions are obtained by empirical estimates, such as initial temperature of cylinder head, initial temperature of cylinder wall and initial temperature of piston. And fuel injection laws of numerical simulation and actuality exist certain differences. But in general, the selection of numerical model is reasonable.

\section{Simulation Result and Discussion}

In diesel engine exhaust emission, particulate matter and nitrogen oxides are main pollutants. They are a evaluation index of the good or bad for single-cylinder diesel engine exhaust emissions.

\subsection{The Characteristics of NOx Emission [5]}

Nitrogen oxides is the main atmospheric pollutants, and it mainly includes $\mathrm{NO}, \mathrm{NO}_{2}, \mathrm{~N}_{2} \mathrm{O}, \mathrm{N}_{2} \mathrm{O}_{3}, \mathrm{~N}_{2} \mathrm{O}_{4}$ and $\mathrm{N}_{2} \mathrm{O}_{5}$. NO and $\mathrm{NO}_{2}$ (referred to as $\mathrm{NOx}$ ), the largest proportion of over $98 \%$. The proportion of $\mathrm{NO}$ and $\mathrm{NO}_{2}$ (referred to as NOx) is the largest of all and more than 98\%. NO is main and the proportion is about $95 \%$ in NOx. Due to the proportion of NO is bigger, we regard NO as main object to study.

The Figure 4 shows that with increase of oxygen content, mean mass fraction of NO in exhaust is corres- 


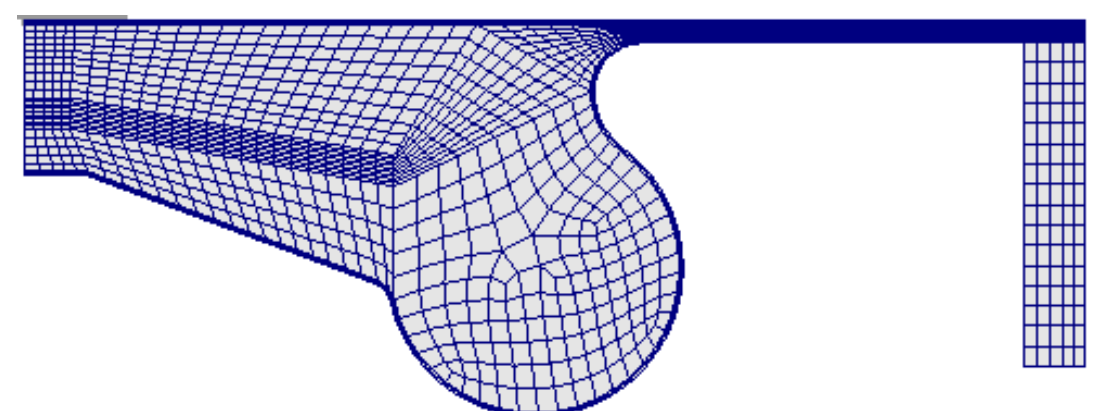

(a)

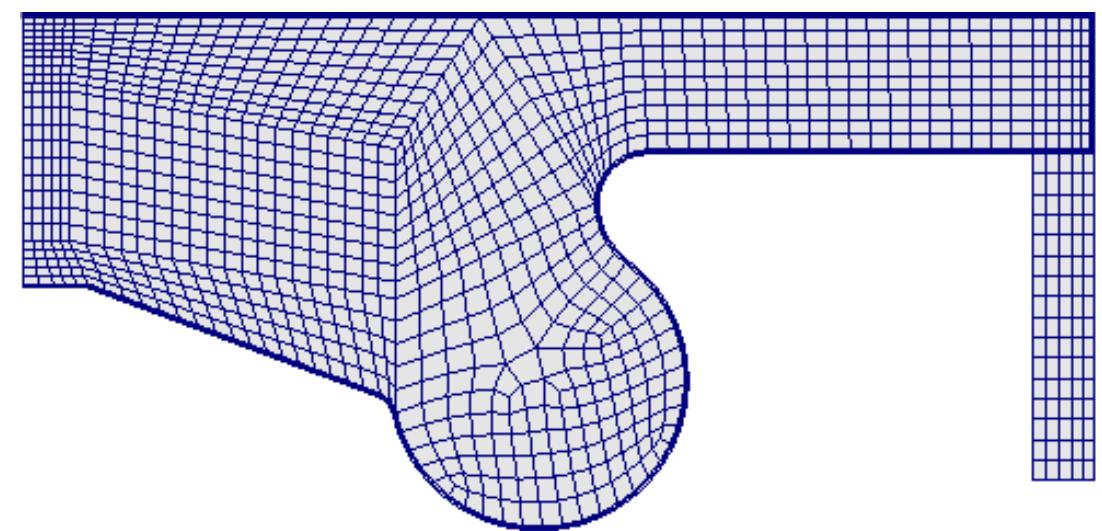

(b)

Figure 2. The grid model of combustion chamber. (a) The grid model of top dead center; (b) The grid model of bottom dead center.

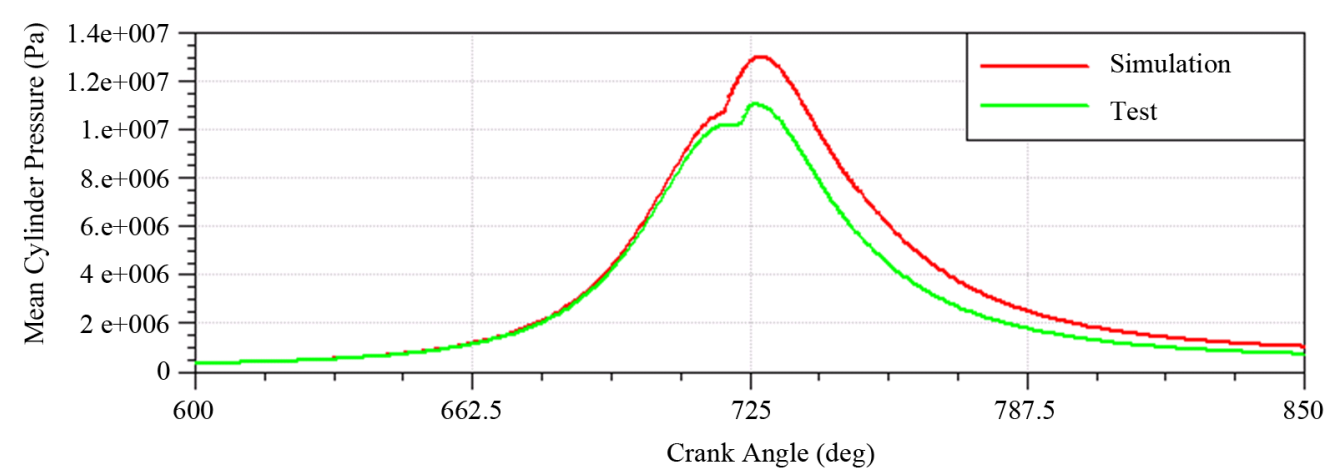

Figure 3. Comparing results of numerical simulation and experiment test.

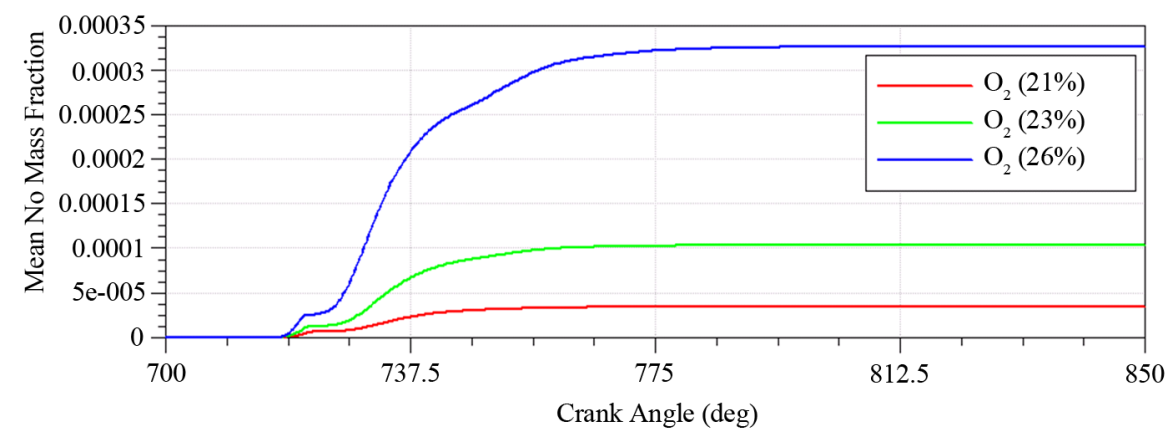

Figure 4. Under different $\mathrm{O}_{2}$, $\mathrm{NO}$ changes along with crank angle. 
ponding increase. The conditions of to produce NO in high temperature and oxygen enrichment are conducive to NO. When the oxygen content is $26 \%$, NO significantly rise. If continuing to add content of oxygen, it will produce a lot of NO and this is not conducive to reduce NO in exhaust pipe. The Figure 5 shows that in the condition of rich oxygen $\left(23 \% \mathrm{O}_{2}\right)$, when the amount of $\mathrm{CO}_{2}[6]$ is not much, mean NO mass fraction will decrease with the increase of $\mathrm{CO}_{2}$. This is due to the high specific heat of $\mathrm{CO}_{2}$ can reduce temperature of combustion chamber and prevent increase of NO. However, when the amount of $\mathrm{CO}_{2}$ is very much, NO will sharp rise.

It shows that when $\mathrm{CO}_{2}$ reaches a certain value, the production of $\mathrm{NO}$ will mainly depend on dilution effect of $\mathrm{CO}_{2}$. But when oxygen content is constant, it has no dilution effect. The Figure 6 shows that when the amount of $\mathrm{CO}_{2}(21 \%)$ is fixed, to increase oxygen content will promote the generation of NO. Accordingly, too much $\mathrm{CO}_{2}$ or too much $\mathrm{O}_{2}$ will increase $\mathrm{NO}$ and a reasonable amount of $\mathrm{CO}_{2}$ and $\mathrm{O}_{2}$ will be conducive to control emissions.

\subsection{The Characteristics of Soot Emission}

Particulate Matter (PM) is another main pollutant in exhaust emissions of diesel engine [7]. It has four parts: Soot, sulfate, SOF and the metal components from lubricating oil and combustion chamber's surface and Soot is main part.

The Figure 7 shows, without additional $\mathrm{CO}_{2}$, the amount of Soot will decline when oxygen content increase. Because of additional $\mathrm{O}_{2}$ can help to burn, the emissions of particulate matter will be reduced. The Figure 8 shows when $\mathrm{O}_{2}$ is rich, adding a little $\mathrm{CO}_{2}$ to combustion chamber, the output of Soot only change a little [8]. However, if add a mass of $\mathrm{CO}_{2}$ to combustion chamber, the output of Soot will greatly reduce. The Figure 9 shows that under the same $\mathrm{CO}_{2}$, increasing $\mathrm{O}_{2}$ will help reduce Soot. Therefore, oxygen-enriched combustion can reduce soot. In addition to, if $\mathrm{CO}_{2}$ instead of $\mathrm{N}_{2}$, when $\mathrm{CO}_{2}$ reaches a certain value, it also will reduce the emissions of soot.

To sum up, appropriate $\mathrm{CO}_{2}(21 \%)$ and $\mathrm{O}_{2}$ (23\%) will be useful for single-cylinder diesel engine to reduce pollutants.

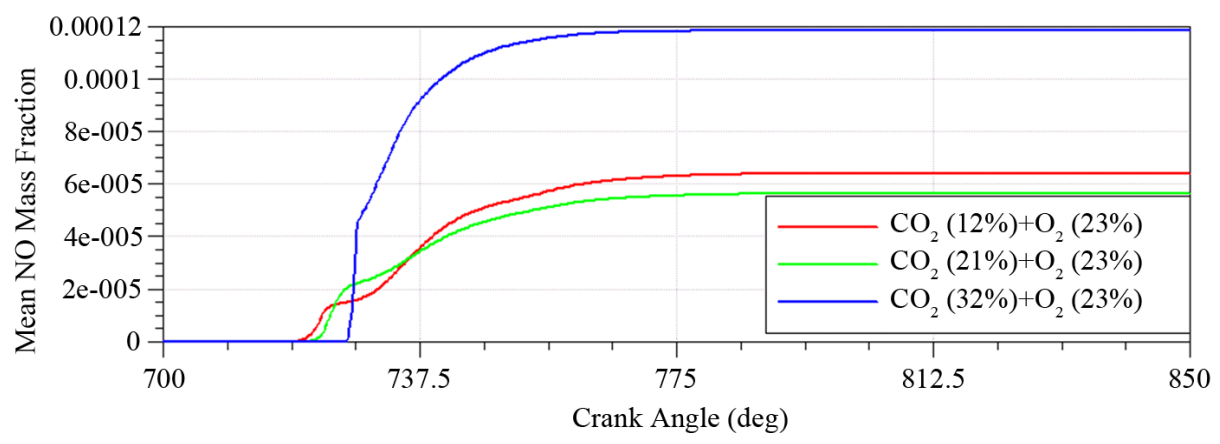

Figure 5. Under rich oxygen, adding different amount of $\mathrm{CO}_{2}$, $\mathrm{NO}$ changes along with crank angle.

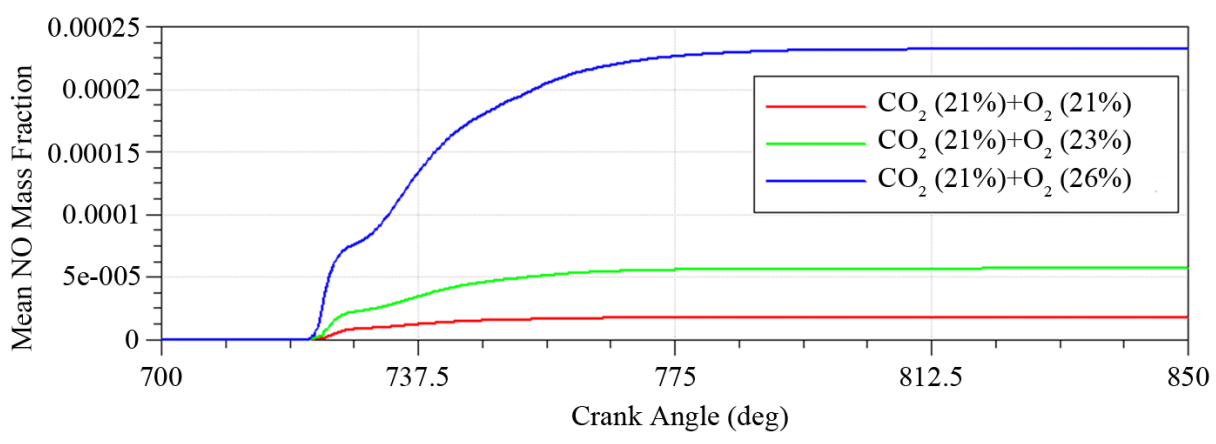

Figure 6. Under same amount of $\mathrm{CO}_{2}$ and different $\mathrm{O}_{2}$, NO changes along with crank angle. 


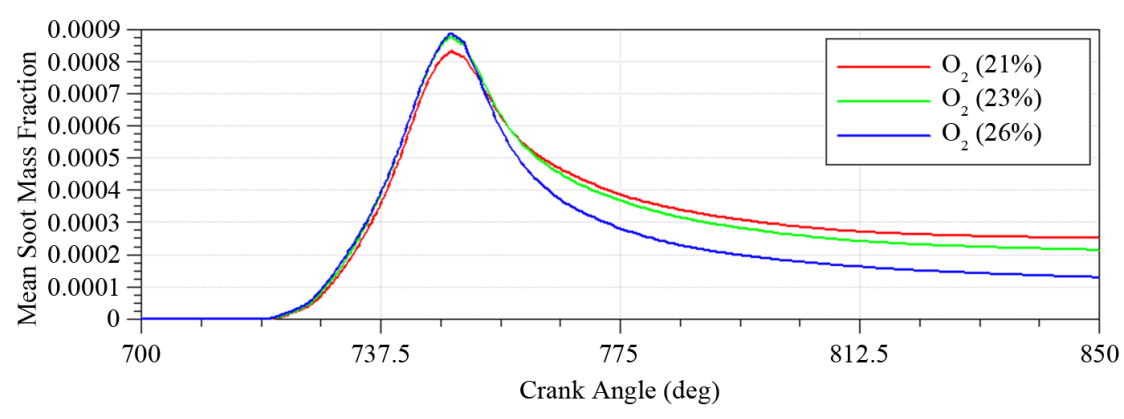

Figure 7. No extra $\mathrm{CO}_{2}$ and different oxygen contents, soot changes along with crank angle.

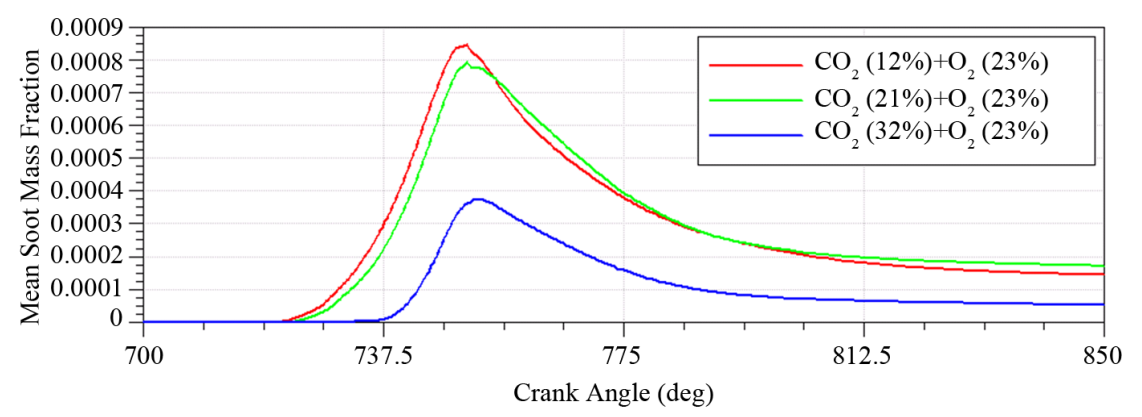

Figure 8. The same oxygen content (rich oxygen) and different $\mathrm{CO}_{2}$, soot changes along with crank angle.

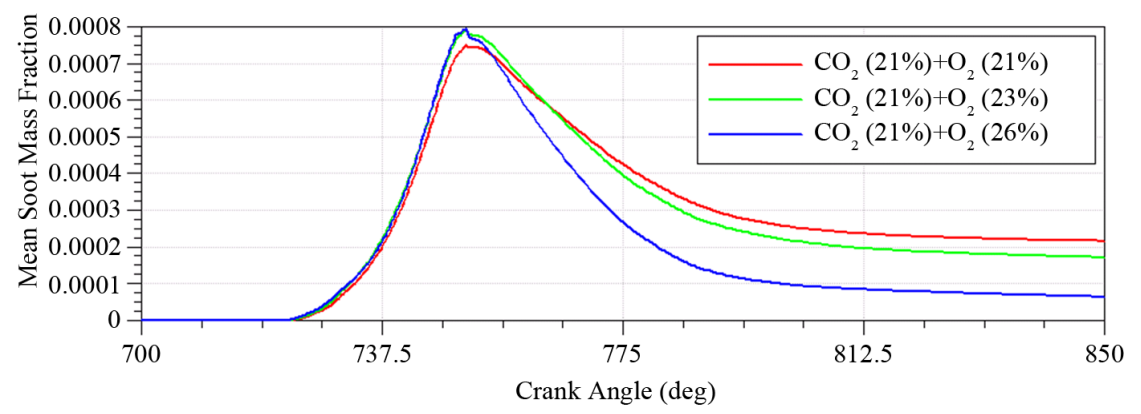

Figure 9. Different oxygen content and the same $\mathrm{CO}_{2}$, soot changes along with crank angle.

\section{Conclusions}

This paper, by means of numerical simulation, studied emission performance of single-cylinder diesel engine of oxygen-enriched, oxygen-enriched + EGR (adding $\mathrm{CO}_{2}$ in inlet) and only EGR.

1) The synergy between EGR and oxygen-enriched combustion contributes to reducing diesel exhaust emissions.

2) On the premise of making comprehensive consideration for emissions of Particulate Matter and NOx, we conclude that $21 \% \mathrm{CO}_{2}+23 \% \mathrm{O}_{2}$ is ideally matched.

Oxygen-enriched combustion can help fuel fully burn, but if $\mathrm{O}_{2}$ is sufficient, temperature of cylinder will rise and it will lead to NOx emissions increase. Just at the moment, by adding $\mathrm{CO}_{2}$ of high specific heat capacity, it can properly reduce NOx. EGR + oxygen-enriched combustion is a new method for diesel engine exhaust after treatment.

\section{Acknowledgements}

The authors acknowledge Shanghai University of Engineering and Science for giving financial supports to this project with No. 15KY0609. This paper is funded by Opening Project of Shanghai Key Laboratory of Multiphase Flow and Heat Transfer in Power Engineering. 


\section{References}

[1] AVL FIRE User Guide (2009) FIRE 2009 Basic Training Beijing and Wuhan. 51-52.

[2] Bunker, B. (2004) International Symposium of the Vehicle Emission Regulations.

[3] Johnson, T. (2006) Diesel Emission Control in Review. SAE Technical Paper 2006-01-0030. http://dx.doi.org/10.4271/2006-01-0030

[4] AVL FIRE User Guide (2014) CFD-Solver_v2014_05_CFD—Solver.

[5] Zhu, J.-J. and Wang, T. (2011) Numerical Simulation of 4100 Diesel Engine Combustion and Emissions.

[6] Edwards, S.P. (1998) The Potential of a Combined Miller Cycle and Internal EGR Engine for Future Heavy Duty Truck Applications. SAE Technical Paper 980180. http://dx.doi.org/10.4271/980180

[7] Montajir, R.Md., Tsunemoto, H., et al. (2001) A New Combustion Chamber Concept for Low Emissions in Small DI Diesel Engines. SAE Technical Paper 2001-01-3263. http://dx.doi.org/10.4271/2001-01-3263

[8] Zhao, E.-L. and Zhang, Y. (2012) Numerical Simulation with Low Temperature Diesel Combustion of Different EGR on High Density. Auto Mobile Science \& Technology, No. 1. 